\title{
STUdies ConCERNING THE AdHERENCE STRENGTH OF SOME THERMOGLUED TEXTILE ENSEMBLES
}

\author{
STEFANUTA, I. \& VLAD, D.
}

Abstract: The paper approaches a less treated topic by the specialists from textile clothing field: the adherence of the thermo-glued under ensembles. This characteristic influences in a big extent the properties of wearing and easy-care of clothing items. In the first part, experimental work and instrument used are highlighted according to the international standards. The tests have been performed on 7 types of basic materials and 2 types of insertions considered more representatives from point of view of utilisation level.The paper is focused onto experiments performed on seven different basic woollen and cotton textile materials and two types of representative insertions with adhesive, as well. The obtained results leaded to the adherence values calculus for these under ensembles. The interpretations provided by the researchers will constitute aspects of basic analyse for the specialists from manufacturing field.

Key words: adherence, insertion, adhesive, thermo gluing
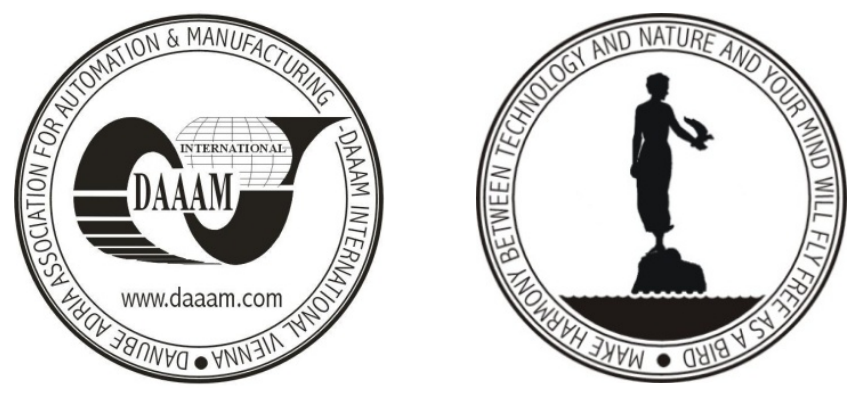

Authors' data: Univ. Prof. Dipl.- eng. Dr. Sc. Stefanuta, I[oan]; Univ. Assist. Dipl. -Eng. Ph. d student Vlad, D[orin], „Lucian Blaga“ University of Sibiu, 10, Victoriei Bd, Sibiu, 550024, Romania; ioan.stefanuta@ulbsibiu.ro, dorin.vlad@ulbsibiu.ro,narcisa.vrinceanu@ulbsibiu.ro

This Publication has to be referred as: Stefanuta, I[oan] \& Vlad, D[orin] (2009). Studies Concerning the Adherence Strength of some Thermoglued Textile Ensembles, Chapter 62 in DAAAM International Scientific Book 2009, pp. 643-652, B. Katalinic (Ed.), Published by DAAAM International, ISBN 978-3-901509-69-8, ISSN 1726-9687, Vienna, Austria

DOI: 10.2507/daaam.scibook.2009.62 